\title{
Towards a Syntactic-Semantic Typology of Presentation Scale Sentences in Fiction Narratives
}

\begin{abstract}
In the framework of FSP every sentence implements one of the dynamic semantic scales, which functionally reflect the distribution of communicative dynamism and operate irrespective of word order. In principle, Firbas distinguishes two types of dynamic semantic scales: the Presentation Scale and the Quality Scale. The present paper looks at the role of the English verb operating in Presentation Scale sentences within fiction narratives from the point of view of both dynamic and static semantics; it also aims at a syntactic-semantic typology of the sentences implementing the Presentation Scale. Specifically, the Firbasian phenomenon of presentation or appearance on the scene is examined and exemplified by means of statistical and FSP analysis of a sample corpus based on a fiction narrative text by C.S. Lewis, viz. The Chronicles of Narnia: The Lion, the Witch and the Wardrobe.
\end{abstract}

Key words

FSP; presentation; verb; scale; narrative; Firbas

\section{Introduction}

For more than a decade, the author's research has been dealing with the theory of functional sentence perspective (FSP), adopting the research methods prolifically elaborated by Firbas and the Brno branch of the Prague School followers (Firbas 1992, 1995, Svoboda 1981, 1989, Dušková 1998, 2008, Chamonikolasová 2005). The principal focus has predominantly been the establishment and operation of the dynamic semantic tracks, the phenomenon of the functional macrofield, se- 
mantic homogeneity, or the manifestation of ideology seen through the optics of FSP (see e.g. Adam 2009). Recently, however, the field of the research interest has been shifted towards the role of the English verb operating typically in the transitional layer of the text, especially in the sentences implementing the socalled Presentation Scale (Pr-Scale) (Adam 2010, Adam and Kudrnáčová 2010). Likewise, the text material analysed has been lately somewhat changed in terms of its genre; while the first research stage was almost exclusively concerned with religious discourse, the recent investigation into the realm of FSP is focused apart from the religious written narratives of the New Testament - on fiction narrative texts.

The present study offers an FSP analysis (both quantitative and qualitative) of the full set of the sentences implementing the Presentation Scale excerpted from C.S. Lewis' The Chronicles of Narnia: The Lion, the Witch and the Wardrobe. The corpus consists of ca 40,000 words and their FSP analyses. Based on what has been said above, the key research objectives may be formulated as follows: (1) the syntactic-semantic typology of Pr-scale sentences, and (2) the semantic character of the English verb functioning within the Presentation Scale (henceforward Pr-verb).

\section{Static vs Dynamic Semantic Analysis}

The theory of FSP - firmly rooted in the functional-structural teaching of the Prague School - explores the information structure of utterances and the relationships between the units of information in the utterance in the immediately relevant context, i.e. at the very moment of utterance. Thus it approaches a piece of language from the dynamic perspective. Advocating a dynamic approach to the semantic analysis, the theory of FSP represents a logical counterpart of what is usually referred to as static semantics. In FSP, semantic content plays a significant role, being actually one of the three basic factors acting in written discourse; it joins the other two factors of the linear modification and the immediately relevant context (Firbas 1992: 14-6). According to Firbas, the sentence is a field of semantic and syntactic relations that in turn provides a distributional field of degrees of communicative dynamism (CD), which is defined as "the extent to which the element contributes towards the development of the communication" (Firbas 1964: 270). As a semantic load of individual communicative units, the dynamic semantics operates on the level of the distribution of the degrees of CD over sentence elements.

It will be worth noting that the Brno tradition of the FSP research (personified in the figure of Jan Firbas) organically connects both the dynamic and the static approaches toward the semantic analysis (sometimes labelled as a dual semantics, e.g. in Dušková 2008: 67). Not only does such a perspective describe language in its complexity, but it also seems to be vital for a thorough semantic analysis of a text, notably in the area of the verb. In the framework of the Firbasian theory 
of FSP the English verb prototypically tends to be the mediator (i.e. transition) between the theme and the rheme (cf., e.g., Firbas 1992 and Adam 2009). At the same time, however, from the point of view of static semantics, verbs represent the main organising elements in the formation of the sentence (it is well known that they shape the sentence in that they play a decisive role in determining participant roles). This seeming contradiction can be "reconciled by appealing to the fact that the formative function of the verb subsumes the verb's mediating (transitional) role (meant here in terms of static semantics)" - in other words, that the verb plays a mediating role both in the dynamic semantic structuration of the sentence and in its static semantic structuration (for more details see Adam and Kudrnáčová 2010).

It has been mentioned that the dynamic understanding of semantics represents an inherent feature of FSP; therefore, the dynamic approach has been prominent in the semantic analysis carried out in the framework of FSP. To illustrate this, there is, as a rule, a direct, straightforward relationship between FSP tripartite functions (theme - transition - rheme) on the one hand and corresponding dynamic semantic roles (functions) on the other: for instance, the Bearer of Quality or the Setting is always thematic, or the Specification is inevitably rhematic (cf. Dušková 2008: 71). Nevertheless, the situation is remarkably different in the case of the verb that - in both the Presentation and the Quality Scales - forms the transition of the sentence, or, if there is no successful competitor in the distributional field, the rheme. Thus, only the verb represents a potentially heterogeneous, double-faced element capable of fulfilling two dynamic semantic functions. As such, the verb (and its role in perspectivising the sentence either towards or away from the subject) definitely deserves a thorough treatment in terms of the dynamic and static semantics.

Among other things mentioned above, the present paper aims to show that static semantics - apart from its traditionally favoured dynamic counterpart - plays an important role in shaping the resultant dynamic semantic scale of a sentence.

\section{The Phenomenon of Presentation on the Scene}

The idea of presentation of an actor on the scene (to stick to the sapient Firbasian tradition of using theatrical terminology) seems to be at the core of human existence and communication. Logically, any act of ours must be naturally preceded by an introduction of the participants of communication. To make use of Mathesius' ideas, it is possible to claim that first one has to present a phenomenon (typically a person, object) to be able to say something about it. Mathesius was the first to notice the language universal of every utterance having a theme and a rheme, and to formulate the basic principles of what was to be labelled FSP only later. According to Mathesius' studies on the Czech word order, the theme of a sentence represented the point of departure, i.e. what is being talked about, while the rheme was connected with the core of the message, i.e. what is being 
said about the theme (Mathesius 1961: 91-92, 1975). Analogously and illustratively enough, in the context of the theatre, the theatre script - before the dialogues are offered - has to announce / present the persons that are going to enter the stage, such as in Enter Hamlet and Players. Enter Polonius, Guildenstern, and Rosencrantz and the like. Only then can the actors act in the true sense of the word and produce their utterances. Though usually infrequent, the sentences that present somebody or something on the scene are obviously vital for further information conveyed by the rest of the text.

As early as the initial stages of his FSP research, Firbas came up with the idea of the so-called dynamic semantic scales that are implemented in sentences (Firbas 1992). In contrast with a static approach towards semantic functions of sentence constituents (e.g. agent, instrument etc.), the dynamic semantic functions may change in the course of the act of communication; the same element may thus perform different functions in different contexts and under different conditions. Generally speaking, every sentence implements one of the dynamic semantic scales, which functionally reflect the distribution of communicative dynamism and operate irrespective of word order. In principle, Firbas distinguishes two types of dynamic-semantic scales: the Presentation Scale and the Quality Scale. In the scales, each element is ascribed one of the dynamic-semantic functions (DSFs) (Firbas 1992).

The Presentation Scale (Pr-Scale), which is under investigation in the present paper, includes three basic dynamic semantic functions: firstly, the scene (Setting; abbreviated as Set) of the action, i.e. typically temporal and spatial items of when and where the action takes place. Secondly, the existence or appearance on the scene is typically conveyed by a verb (Presentation of Phenomenon; Pr) and, thirdly, the major, most dynamic element (Phenomenon; $\mathrm{Ph}$ ) is literally ushered onto the scene:

\section{(1) A hush (Rh; Ph) fell (Tr; Pr) on the crowd (Th; Set). (N 151b)}

Recently, a special sub-type of Pr-Scale was detected and described (see especially Chamonikolasová 2005, or Adam and Chamonikolasová 2005); it was labelled the Extended Presentation Scale. The structure of sentences implementing this type of interpretative scale actually corresponds very closely to the Presentation Scale, differing only in the presence of the Specification, which is not part of the pure Presentation Scale as defined by Firbas.

(2) Nymphs who lived in the wells and Dryads who lived in the trees ( $\mathrm{Rh} ; \mathrm{Ph})$ came out (Tr; Pr) to dance with the Fauns (Rh; Sp). (N 19d)

At this point, it is inevitable to address one more aspect of FSP interpretation. It has been noted above that the verb operating in Pr-Scale sentences (Pr-verb) presents something new on the scene. In relation to their presentation role, Firbas claims that it does so "if it expresses the existence or appearance on the 
scene with explicitness or sufficient implicitness" (Firbas 1995). Prototypically, these are verbs such as come, appear, occur, turn up, etc. The point is that also other types of verbs are apparently capable of expressing the existence or appearance on the scene even though they do not convey the meaning of appearance in a straightforward manner; in other words, they do so with sufficient implicitness. One of the subsidiary research objectives then may be formulated as follows: what are the syntactic-semantic features that enable the verb to act as a Pr-verb and thus present a Phenomenon on the scene? This issue is discussed in detail in Section 6 of the present text.

\section{Corpus and Basic Statistics}

As has been said above, the whole text under examination consists of ca 40,000 words and their FSP analyses. Within the corpus, there are 3,067 basic distributional fields, which are technically counted as finite clauses; non-finite clauses are regarded as separate communicative units within the basic distributional fields.

Since the topic of the discussion is the occurrence and typology of sentences that implement the Presentation Scale, these were excerpted, arranged and tagged in the research corpus. Namely, the first column of the chart signifies the subtype (the classification of the subtypes will be treated in Section 5 in detail), the second one offers the individual basic distributional fields, and the last one offers the source in the corpus by referring to the page in the book ( $\mathrm{N}$ stands for The Chronicles of Narnia). In addition, if there are more Pr-sentences on the same page, lower-case letters are used to differentiate separate fields, such as in N72a.

Table 1. Sample Fraction of the Corpus

\begin{tabular}{|c|l|c|}
\hline $\begin{array}{c}\text { Sub- } \\
\text { type }\end{array}$ & \multicolumn{1}{|c|}{ Sentence } & Source \\
\hline 1 & There are the trees. & N69b \\
\hline 1 & But there are trees that would betray us to her; & N69c \\
\hline 2 & And now a very curious thing happened. & N70 \\
\hline 2 & Just below them a dam had been built across this river. & N71 \\
\hline 1 & $\begin{array}{l}\text { Above the dam there was what ought to have been a deep } \\
\text { pool but was now, of course, a level floor of dark green ice. }\end{array}$ & N72a \\
\hline 3 & And below the dam, much lower down, was more ice. & N72b \\
\hline
\end{tabular}

Out of all the 3,067 basic distributional fields in the corpus material, 247 instances of sentences that implement the Presentation Scale were identified, which represents 8.05 percent. Apparently, a low number of the basic distributional fields in the corpus follow the pattern of the Pr-Scale. It is possible to claim, however, that the number of Pr-scale occurrences is - in comparison with other texts - still rela- 
tively high. To illustrate, in other fiction narrative texts under scrutiny in terms of FSP (viz. works by Čapek, Leacock, and Wilde respectively) the incidence of sentences implementing the Pr-Scale is usually about 5-7 percent (see the results published by Řezníčková, I. 2009; Wachsmuthová 2009; Tillhonová 2009).

For the sake of a complete picture of the corpus, below is a table that represents in absolute numbers and percentage the statistics of occurrence of sentences implementing Pr- or Q-Scale respectively in the corpus.

Table 2. Statistical Data of the Corpus

\begin{tabular}{|l|c|r|}
\hline \multicolumn{1}{|c|}{ Basic distributional fields } & Occurrence & \% \\
\hline Q-Scale & 2,820 & 91.95 \\
\hline Pr-Scale & $\mathbf{2 4 7}$ & $\mathbf{8 . 0 5}$ \\
\hline Total & 3,067 & 100.00 \\
\hline
\end{tabular}

\section{Syntactic-Semantic Classification of Pr-sentences}

With regard to a preliminary typology of Pr-Sentences, the corpus data were processed in terms of different syntactic subtypes. To be precise, four separate syntactic patterns were identified and labelled as Subtypes 1-4 (see below). Incidentally, though carried out independently, the classification acquired is virtually in harmony with what Dušková offers in her study on differentiation of the syntactic forms of the Presentation Scale (cf. Dušková 1998). Below, individual subtypes will be discussed and illustrated by examples one by one.

\section{Subtype 1: Existential construction}

By far the most frequent subtype of Pr-Scale sentences is definitely represented by the existential construction (64\%). The existential there-clauses represent a somewhat specific phenomenon in the area of FSP interpretation; it may cause difficulties in assigning the dynamic-semantic functions to the units. Firbas speaks, in this connection, of "permanent obviousness" of the there-constructions in the immediately relevant context (Firbas 1992: 24). For the writer and the reader it is obvious what this there-element means and hence its notion is permanently present in the situational context. Firbas argues that this construction, "though semantically very weak, is not totally stripped of all meaning, [...] and acts as an indicator of a scene expressed by a genuine adverbial of place" (Firbas 1992: 24). Some authors even dispute any original semantic load of the existential there; what is crucial, though, is the fact that the existential construction explicitly indicates existential predication, which is a constitutional component of the syntactic-semantic structure of the Presentation Scale (cf. Dušková 2005). Consequently, the existential there is invariably assigned the Set-function and is entirely context-dependent. Interestingly 
enough, besides the thematic existential there, only exceptionally is there another thematic Setting in the sentences of Subtype 1 in the corpus.

It is also worth mentioning that the existential there-clauses are specific in their linear modification, i.e. word order arrangement: unlike most sentences that implement the Pr-scale, in the existential clauses the notional subject is invariably postponed towards the end of the sentence. In other words, the Phenomenon is not presented in the initial part of the sentence, but on the contrary, it actually represents the culmination peak of the information structure; the English grammatical principle requiring the SVO wording is thus overridden by the linear modification FSP factor. In relation to this aspect, Dušková points out that not only is the existential construction the most frequent regarding the Pr-Scale sentences, but also "the only neutral form in the sense of being unmarked with respect to deviation from both the grammatical word order and the basic distribution of communicative dynamism" (Dušková 2005: 17).

(3) There'll be hawks. (N9c)

(4) There's a wireless and lots of books. (N10a)

(5) There are only three possibilities. (N51a)

In example (3), for instance, the notional subject (hawks) is context-independent and conveys the information towards which the communication is perspectived. Thus, it carries the highest degree of $\mathrm{CD}$ and performs the Ph-function. The verbal element is then transitional and mediates between the theme and the nontheme (for a detailed discussion of the existential there-clause, see also Firbas 1992: 24, 59 and Breivik 1983). Variably, the classical there+be construction may be realised as there+verb other than be:

(6) Instantly there appeared a round box, tied with green silk ribbon... (N38c)

(7) Out of the hair there stuck two horns. (N13c)

Among other things, the corpus findings show that a relatively large number of existential contractions manifest the use of a negative element, such as no, not, nothing, none, never, etc. It seems that the frequent occurrence of negation in existential constructions has to do with the presentation of something new on the scene, even if in such cases it concerns rather a non-existent element:

(8) But there's never been any of your race here before. (N82a)

(9) And of course there was no chance of going back to get it now. (N91a)

\section{Subtype 2: Rhematic subject in preverbal position}

The second most recurring subtype of the Pr-Scale sentence pattern may be described as that with a rhematic subject in initial, preverbal position $(22 \%)$; it is 
undoubtedly the prototypical, "canonical" type connected with the Presentation Scale. In it, the initial sentence element is typically represented by a context-independent subject, which is only then followed (in concord with the requirements of the English word order principles) by the verb, which expresses existence or appearance on the scene. The sentence may be also opened with a scene-setting temporal or spatial thematic adverbial (see e.g. (11)), the position of which is quite volatile - compare (11) and (12); end-focus is not applied, though (cf. Subtype 3). Exceptionally, the Pr-Scale sentence is further syntactically and semantically broadened by a Specification and thus implements the Extended Pr-Scale (cf. (10)):

(10) Nymphs who lived in the wells and Dryads who lived in the trees came out to dance with the Fauns. (N 19d)

(11) And now a very curious thing happened. (N70)

(12) A slow cruel smile came over the Witch's face. (N99b)

Obviously, the word order of this subtype actually violates the end-focus principle observed in English. If fully implemented, linear modification induces the sentence elements to manifest a gradual rise in $\mathrm{CD}$ in the direction from the beginning to the end of the sentence. In other words, as Bolinger claims, "gradation of position creates gradation of meaning, when there are no interfering factors" (Bolinger 1952: 288). It should be recalled at this point that while in Czech the FSP linearity principle represents the leading power governing the syntax of sentences (i.e. the further an element is in the sentence the more prominence it carries), in English the prominent word order principle is the grammatical one. The English sentence has to satisfy the requirements of ordering the individual sentence elements in accordance with their syntactic functions. Nevertheless, sentences with a rhematic subject in preverbal position are, as a rule, considered unmarked by native speakers of English (exceptions may be observed in connection to prosodic re-evaluating intensification; cf. Firbas 1992: 154-156).

A special subcategory is then represented by sentences in which the verb of appearance manifests itself in a passive form, such as in:

(13) Just below them a dam had been built across this river. (N71)

(14) Word has been sent that you are to meet him. (N81b)

Passive constructions follow the same pattern of a context-independent subject and a Pr-verb; the scene is prototypically set by an adverbial. Both the example (13) and (14) represent a somewhat special case of a syntactic discontinuity, in (14) it is realised by a that-clause. Whereas (13), owing to the initial thematic adverbial, could be used without the discontinuity (Just below them a dam across this river had been built), such arrangement is unlikely in the example (14). The primary reason for the use of passive in these sentences is obviously the vagueness of the agent. It seems that the passive construction within Pr-Scale sentences 
enables certain detachment from the agent of the action and so allows for the grammatical subject to be highlighted. Such Pr-verbs usually come from the lexical field of so-called verba efficiendi (i.e. verbs of production) - such as build or make; the result of the action is a particular production (cf. Firbas 1992: 62-63).

\section{Subtype 3: Fronted Adverbial \& $S$ - V inversion}

In this subtype, an adverbial is fronted and the subject is highlighted through the principle of end-focus (NB: unlike Subtype 2); as a result, subject - verb inversion takes place. The subject is, of course, context-independent and the verb fulfils the role of presentation on the scene. Such presentation constructions are usually used in literary style and, therefore, their incidence in the corpus is relatively high (13\%).

(15) And next to Aslan stood two leopards of whom one carried his crown and the other his standard. (N125)

(16) Behind them were coats hanging on pegs / and in front of them were snowcovered trees. $(\mathrm{N} 57 \mathrm{~b}+\mathrm{c})$

(17) And here's a packet of tea. (N100b)

Example (17) is an instance of a fronted adverbial here. At first sight, it may seem to perform an analogous role to the existential there; however, it is not so grammaticalised and carries without any doubt locative meaning.

\section{Subtype 4: Locative Th-subject \& Rh-object}

(18) The banner bore a red rampant lion fluttering in the breeze. (N123d)

(19) Inside, the cave had the damp feel and smell of a place that had not been lived in for several days. (N59d)

By far the least frequent subtype of Pr-Scale sentences (1\% in the corpus) is modelled by a peculiar transitive construction that - at least at first sight - seems to implement the Quality, rather than the Presentation Scale, displaying a thematic subject and a rhematic object. Nevertheless, such an approach would adopt only a surface stance. In its deep structure (stipulated both by FSP and its semantic roles), the sentence "the scene-setting nature of the subject (the theme) finds expression in adverbial construction, while the phenomenon appearing on the scene (the rheme) assumes the syntactic function of a subject" (Dušková 1998: 40). This interpretation may be corroborated by two other semantically corresponding syntactic variants of (18): 
Finally, it should be said that the relative incidence of the four subtypes that were identified in the corpus appears to be dependent on the text genre and register. Whereas the corpus under discussion (fiction narrative) displays the highest number of the existential construction (64\%), other text types manifest preference of the rhematic subject in preverbal position (e.g. in Biblical narratives with theological load it is ca $76 \%$ vs. $21 \%$ of existential constructions!). Also the overall number of Pr-Scale sentences may substantially differ in terms of various text types; e.g. religious written discourse generally displays higher percentage of $\mathrm{Pr}$ Scale sentences, such as ca $12 \%$ in New Testament gospels and Pauline epistles (see Adam 2010 and Lingová 2008). Below is a summative chart with the individual incidence of the four subtypes of Pr-sentences discussed above:

Table 3. Incidence of the Subtypes of Pr-sentences

\begin{tabular}{|l|r|r|}
\hline \multicolumn{1}{|c|}{ Pr-Scale Sentences } & Occurrence & \multicolumn{1}{c|}{$\%$} \\
\hline Subtype 1 - Existential construction & 158 & 64 \\
\hline Subtype 2 - Rhematic subject in preverbal position & 54 & 22 \\
\hline Subtype 3 - Fronted adverbial \& S-V inversion & 32 & 13 \\
\hline Subtype 4 - Locative Th-subject & 3 & 1 \\
\hline Total & 247 & 100 \\
\hline
\end{tabular}

\section{Pr-verbs: preliminary semantic classification}

Within the theory of FSP, the verb in English is perceived as relatively semantically weak; for instance Vachek claims that "in English the old Indo-European function of the verb i.e. that of denoting some action has been most perceptibly weakened (Vachek 1995: 23). Apart from that, operating within an analytical language, "the English finite verb form appears to be much less dynamic in character (...) and frequently ceases to be the unmatched instrument of predication, being often reduced to something that very closely resembles a copula" (Vachek 1976: 342). In the context of FSP, the English verb tends to be the mediator (or transition) between the theme and the rheme. Under the circumstances, the verb either ascribes a quality to the subject, bridging its specification, or presents something new on the scene if it expresses the existence or appearance on the scene with "explicitness or sufficient implicitness" (Firbas 1995: 65; cf. Adam 2009: 92-4).

As has been noted above, semantically, however, the English verb seems to play a vital role in constituting and perspectivising the sentence. Since the topic of the present paper is the sentences that implement the Presentation Scale, only the Pr-verbs will be examined in this section. It is important to recall that, ac- 
cording to Firbas $(1992,1995)$, the Pr-verbs express existence or appearance on the scene with explicitness or sufficient implicitness. The corpus findings contain instances of both verbs that do so in an explicit way and those which achieve the same semantic goal in a more-or-less implicit manner.

\section{Explicit expression of existence or appearance on the scene}

The corpus data revealed basically two static semantic groups of verbs that may be seen clearly as those expressing the existence or appearance on the scene in an explicit way. First, these are verbs of going and coming - e.g. come, arrive, enter, step in, fall, rush up, step out, come down; second, these are verbs that convey the notion of appearance proper, such as appear, occur, be born, turn up, go up.

The Pr-verbs falling into the category of verbs of going and coming are, in their nature, dynamic and carry the meaning of certain motion. Fulfilling the Firbasian idea of existence on the scene, they mediate this existence from the dynamic point of view, placing emphasis on the motion process proper. Cf.:

(22) And a soon after that a very strange person stepped out from among the trees. (N13b)

(23) ... and from a hole in the roof smoke was going up. (N72a)

Such Pr-verbs denote a simple movement action performed by the phenomenon that is being presented on the scene of communication. The set of verbs as such is not extremely varied as to the meaning carried by the verbs; these verbs rather convey simple motion actions such as that of going, coming, following, or returning that actually lack any further specification of a more subtle meaning. In other words, it is the final localization of the mover that is semantically most prominent. As Kudrnáčová says, such verbs deal with physical translocation, rather than manner of motion; the culmination point is thus usually highlighted (Kudrnáčová 2008).

The verbs of appearance proper in their nature actually exactly reflect the definition of Firbasian appearance on the scene with explicitness. Such Pr-verbs are concerned more with the appearance per se rather than with the motion involved. It is possible to speak of appearance as a non-scalar, polar phenomenon; somebody or something appears on the scene without any prior presence, i.e. from zero to full existence. Analogously to the findings discussed in the present paper, Kudrnáčová claims that "the intrinsically contrastive character of (dis)appearance is underlain by the strict bipolarity of the path, lacking a transitional phase (Kudrnáčová 2008, 47).

(24) ... and horrible ideas came into his head. (N73b)

(25) Instantly the same dwarf whom Edmund had seen with her before appeared. (N99c) 


\section{Implicit expression of existence or appearance on the scene}

Interestingly, all different sorts of verbs, such as send, strike, await, buzz, wake (the silence), chirp, shine were identified in the research corpus. Seemingly, they come from different semantic groups of verbs and do not have much in common. The question may arise: what is the implicit semantic load that enables a verb to serve as Pr-verb in the Presentation Scale? What and where are the boundaries between the maximum degree of implicit expression of existence or appearance on the scene and a verbal content that allows "only" for a qualitative use of the verb in the Quality Scale?

The research shows that one of the most significant features of such Pr-verbs may be described as a certain degree of semantic affinity between the Pr-verb itself and the clause subject (cf. Firbas 1992: 60). In other words, the action is so semantically inherent and subject-related that it is the subject that takes over the communicative prominence at the expense of power of the verbal content. The static semantics of the verb then - even if expressing a specific type of action - is reduced to that of presentation.

(26) A bee buzzed across their path. (N120e)

(27) At that moment a strange noise woke the silence. (N128)

(28) ... and gold flashed. (179d)

Apart from the verbs denoting visual, acoustic and other sensory manifestation of an action (see ex. (26) - (28), the Pr-verbs may be recruited from the semantic category of verbs denoting natural phenomena that are typically unaffected by people, such as weather - see (29) and (30). The presentational interpretation may be easily corroborated both by the placement of the nuclear stress on the rhematic subject in English and by the Czech corresponding equivalent translation of the clauses in which the rhematic subject - according to the principle of end-focus invariably occupies the final position in the sentence - cf. (31) and (32).

(29) Then a wind sprang up. (N92a).

(30) And the moon came out. (N92c)

(31) Pak se zvedl vítr.

(32) A vyšel měsíc.

The action content of the verbal element is so natural and typical of the agent (cf. buzzing and the bee, or flashing and gold) that the full verb is employed - from the point of view of dynamic semantics - to denote a form of existence or appearance on the scene. The verb that operates in semantic affinity with its subject semantically supports the character of the subject; in relation to this phenomenon; Firbas argues that via such semantic affinity "the verb prepares the way for the phenomenon to be presented" (Firbas 1992: 61). To be more specific, the corpus findings show that $33 \%$ of all sentences of Subtype 2 (rhematic subject in prever- 
bal position) manifests such semantic affinity. Such occurrence seems to reveal a significant semantic feature of what may be considered to express existence or appearance on the scene in an implicit way.

In his summarising monograph, Firbas enumerates a number of Pr-verbs identified in his corpora (Firbas 1992); here are some of these in alphabetical order: arrive, be in sight, become plain, come forward, come into view, come up, crop up, emerge, exist, evolve, develop, grow out of, happen, issue, recur, rise, spring up, show up, take place, etc. (for a full account of the Pr-verbs given by Firbas, see Firbas 1992: 60-64). It can be readily claimed that all of these verbs are in terms of their degree of expressing existence or appearance on the scene in an explicit or sufficiently implicit way - in full concordance with what the present analysis and current research suggest (see also Dušková 2008). To name just a few Pr-verbs for the sake of illustration, here are those that were not detected by Firbas: be on the move, come out, come over, fall, happen, rush up, lie, sit, stand, stick, strike down, or sweep into sight. The full range of Pr-verbs along with a more profound semantic analysis is a matter of future research in the field.

\section{Conclusions}

The analysis of the corpus data definitely speaks in favour of a fruitful interface of both the dynamic semantics (FSP) and static semantics towards language material. Not only is such a complex approach a helpful tool for a more in-depth FSP analysis, but it also appears to make the FSP interpretation more precise. At times, the dynamic-static semantic analysis in the confines of FSP is capable of eliminating cases of potentiality (especially in relation to the phenomenon of semantic affinity).

Regarding the outlook for future research, there are several vistas open that obviously deserve attention. First, a larger list of Pr-verbs and their analysis based on more representative corpus should be made, along with a more detailed analysis of the syntactic semantic features of Pr-sentences and Pr-verbs (besides their semantic make-up, especially their syntactic characteristics such as valency, complementation or transitivity should be thoroughly explored). In addition, a functional comparison of various genres and registers in terms of Pr-Scale sentences should identify further significant differences, such as the ratio of Subtype 1 vs. Subtype 2 constructions mentioned briefly above. All these issues - in more general terms - represent promising steps in FSP research into the phenomenon of presentation.

\section{References}

Adam, Martin (2009) Functional Microfield Perspective: A Religious Discourse Analysis Based on FSP. Brno: Masaryk University. 
Adam, Martin (2011) 'A Functional Characterology of the English Transitional Pr-Verbs: Presentation or Appearance on the Scene Revisited'. Ostrava Journal of English Philology 2, 7-20.

Adam, Martin and Kudrnáčová, Naděžda (2010) 'Dynamic and Static Semantics of the English Verb in Motion Events: An Attempt at an Integrated Approach'. Topics in Linguistics 6, 29-33.

Bolinger, Dwight Le Merton (1952) 'Linear modification'. Publications of the Modern Language Association of America 67, 1117-1144.

Breivik, Leiv Egil (1983) Existential 'There'. Bergen: University of Bergen.

Dušková, Libuše (1998) 'Syntactic forms of the presentation and their differentiation'. Linguistica Pragensia 8 (1), 36-43.

Dušková, Libuše (2005) 'From the Heritage of Vilém Mathesius and Jan Firbas: Syntax in the Service of FSP'. In: Chovanec, Jan (ed.) Theory and Practice in English Studies 3: Proceedings form the $8^{\text {th }}$ Brno Conference of English, American and Canadian Studies. Brno: Masaryk University, 7-23.

Dušková, Libuše (2008) 'Vztahy mezi sémantikou a aktuálním členěním z pohledu anglistických členů Pražského lingvistického kroužku’. Slovo a slovesnost 69 (1/2), 67-77.

Chamonikolasová, Jana (2005) 'Dynamic semantic scales in the theory of functional sentence Perspective'. In Panevová, Jarmila and Barbora Vidová-Hladká (eds) Aleg(r)ace pro Evu. Papers in Honour of Eva Hajičová. Praha: MFF UK, 61-67.

Chamonikolasová, Jana and Adam, Martin (2005) 'The Presentation Scale in the Theory of Functional Sentence Perspective'. In: Čermák, Jan. et al. (eds) Patterns. A Festschrift for Libuše Dušková. Praha: Filozofická fakulta Univerziy Karlovy, 59-69.

Firbas, Jan (1964) 'On defining the theme in functional sentence analysis'. Travaux Linguistiques de Prague 1, 267-280.

Firbas, Jan (1992) Functional Sentence Perspective in Written and Spoken Communication. Cambridge: Cambridge University Press.

Firbas, Jan (1995) 'On the thematic and the rhematic layers of a text'. In: Wårwik, Brita, SannaKaisa Tanskanen and Risto Hiltunen (eds) Organization in Discourse: Proceedings from the Turku Conference, Anglicana Turkuensia 14, 59-72.

Kudrnáčová, Naděžda (2008) Directed Motion at the Syntax-Semantics Interface. Brno: Masaryk University.

Lingová, Lenka (2008) Some Aspect of the Dynamic - Semantic Tracks within the Theory of FSP. An unpublished Diploma thesis. Brno: Masaryk University.

Mathesius, Vilém (1961) Obsahový rozbor současné angličtiny na základě obecně lingvistickém. Praha: Nakladateltsví Československé akademie věd.

Mathesius, Vilém (1975) A Functional Analysis of Present Day English on a General Linguistic Basis. Praha: Academia (transl. by L. Dušková).

Rezníčková, Ivana (2009) 'Thoughts on the semantic relationship between direct speech and reporting clause with regards to FSP'. Ostrava Journal of English Philology 1, 67-77.

Svoboda, Aleš (1981) Diatheme. Brno: Masarykova univerzita.

Svoboda, Aleš (1989) Kapitoly z funkčni syntaxe. Praha: Státní pedagogické nakladatelství.

Tillhonová, Gabriela (2009) Dynamic semantic tracks in fairy tales. An unpublished Diploma thesis. Brno: Masaryk University.

Vachek, Josef (1976) Selected Writings in English and General Linguistics. Praha: Academia.

Vachek, Josef (1995) A Functional Syntax of Modern English. Brno: Masarykova univerzita.

Wachsmuthová, Zuzana (2009) On Some Aspects of Semantic Homogeneity (Based on FSP Analysis). An unpublished Master's thesis. Brno: Masarykova univerzita. 


\section{Source}

Lewis, Clive Staples (1950) The Chronicles of Narnia. The Lion, the Witch and the Wardrobe. London: Harper Collins.

Martin Adam is Assistant Professor in the Department of English Language and Literature, Faculty of Education, Masaryk University in Brno. He is a member of the Linguistic Section and teaches Functional and Communicative Syntax, Text Analysis and other linguistic disciplines. His professional interest includes above all research in the Firbasian theory of functional sentence perspective (FSP). He is the author of A Handbook of Functional Sentence Perspective (FSP in Theory and Practice) (2007) and a monograph on FSP within religious discourse titled Functional Microfield Perspective: A Religious Discourse Analysis Based on FSP (2009 [2006]).

Address: Mgr. Martin Adam, Ph.D., Department of English Language and Literature, Faculty of Education, Masaryk University, Poříčí 7, 60300 Brno, Czech Republic. [email: martinadamcz@, yahoo.com] 
